\title{
B-DNA Helix Stability in a Solvent-Free Environment
}

\author{
Erin Shammel Baker and Michael T. Bowers \\ Department of Chemistry and Biochemistry, University of California, Santa Barbara, California, USA
}

B-DNA is the most common DNA helix conformation under physiological conditions. However, when the amount of water in a DNA solution is decreased, B-to-A helix transitions have been observed. To understand what type of helix conformations exist in a solvent-free environment, a series of poly $\mathrm{d}(\mathrm{CG})_{n}$ and mixed sequence DNA duplexes from 18 to $30 \mathrm{bp}$ were examined with circular dichroism (CD), ESI-MS, ion mobility, and molecular dynamics. From the CD spectra, it was observed that all sequences had B-form helices in solution. However, the solvent-free results were more complex. For the poly $\mathrm{d}(\mathrm{CG})_{n}$ series, the $18 \mathrm{bp}$ duplex had an A-form helix conformation, both A- and B-helices were present for the $22 \mathrm{bp}$ duplex, and only B-helices were observed for the 26 and $30 \mathrm{bp}$ duplexes. Since these sequences were all present as B-DNA in solution, the observed solvent-free structures illustrate that smaller helices with fewer base pairs convert to A-DNA more easily than larger helices in the absence of solvent. A similar trend was observed for the mixed sequence duplexes where both an A- and B-helix were present for the 18 bp duplex, while only B-helices occur for the larger 22, 26, and $30 \mathrm{bp}$ duplexes. Since the solvent-free B-helices appear at smaller sizes for the mixed sequences than for the pure $\mathrm{d}(\mathrm{CG})_{n}$ duplexes, the pure $\mathrm{d}(\mathrm{CG})_{n}$ duplexes have a greater A-philicity. (J Am Soc Mass Spectrom 2007, 18, 1188-1195) (C) 2007 American Society for Mass Spectrometry

$\mathrm{T}$ The crucial role DNA plays in encoding genetic information and in transporting it from one cell to another makes evaluating its structure and conformational changes essential to fully understand how it functions. Many different conformations of DNA helices have been detected since Watson and Crick discovered the B-form double helix in 1953 [1]. Three of the most common helix conformations are the A-, B-, and Z-forms shown in Figure 1a. Under normal physiological conditions, DNA duplexes are usually present in a B-helix, which is an antiparallel right-handed helix with the base pairs oriented perpendicular to the helical axis [2, 3]. A-DNA is another right-handed helix, but it is shorter and wider than B-DNA, and it is predominantly observed in low humidity conditions [4]. Z-DNA is a very interesting form of DNA because it forms a left-handed helix, more elongated and slender than B-DNA, which is primarily observed in alternating cytosine/guanine rich sequences under high salt concentrations [5]. Although these three forms of DNA are the most common, there are many other DNA helices that possess small variations from the $\mathrm{A}-_{-}, \mathrm{B}-$, or $\mathrm{Z}$ forms.

Due to the flexibility of DNA, transitions from one helix form to another readily occur under certain conditions. One of the first reversible structural transitions

Address reprint requests to Dr. M. T. Bowers, Department of Chemistry and Biochemistry, University of California, Santa Barbara, CA 93106-9510, USA. E-mail: bowers@chem.ucsb.edu observed in a biomolecule was the transition from B-DNA to A-DNA, which was first detected nearly fifty years ago (Figure 1b) [6]. Although the B-helix is recognized as the standard helix form for DNA, the B-to-A (B-A) transition is thought to be very important biologically as the presence of the TATA-binding protein $[7,8]$ and certain polymerases have been observed to induce this transition [9-14]. B-A transitions have also been observed when alcohols and some salts are added to a DNA solution, decreasing its relative humidity (RH) [15-19]. To further understand this dependence on RH, many different DNA duplex sequences have been analyzed with varying solution conditions. One interesting finding was that the B-A transition is sequence-specific and duplexes rich in G-C base pairs undergo the transition more easily than duplexes rich in A-T base pairs [20]. To understand this trend, computer simulations were used to evaluate all the bases, and it was found that cytosine could easily switch its sugar conformation from $\mathrm{C}^{\prime}$ '-endo to $\mathrm{C}^{\prime}$-endo, while the other bases could not switch as readily [21, 22]. Since sugar puckering is one of the main criteria for distinguishing B- and A-form DNA (C2'-endo versus C3'endo), this finding appears to be a good speculation for the greater A-philicity of G-C base pairs.

Understanding the sequence specificity of the B-A transition is extremely important, since the propensity of a given sequence towards an A- or B-form helix is one of the key factors in protein-DNA interactions. Recently, DNA duplexes from 2 to $14 \mathrm{bp}$ were studied 
a)

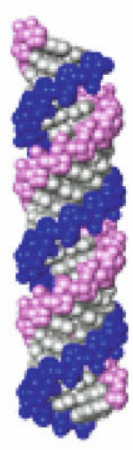

A

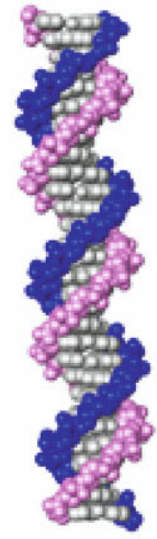

B

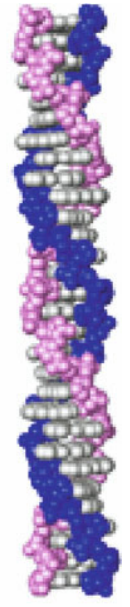

Z b)

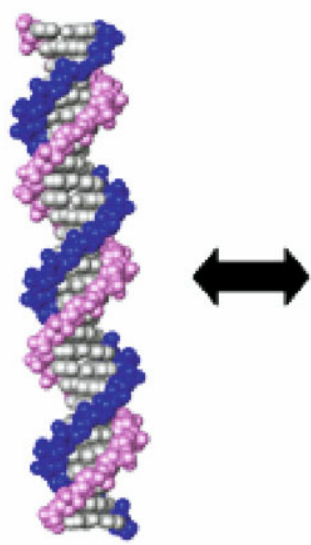

B

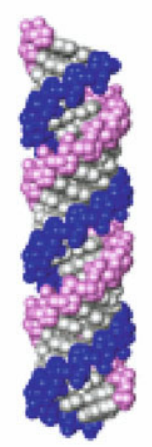

A
Figure 1. (a) A-, B-, and Z-form helices. (b) The B-to-A transition is a common transition that is dependent on the relative humidity of a solution and the DNA sequence. B-DNA is found at high RH, while A-DNA is present at low RH. G-C pairs are also more A-philic than A-T pairs, causing G- and C-rich sequences to undergo B-to-A transitions more easily. One DNA strand is shown in blue, the other in pink, and all bases are gray.

with circular dichroism (CD) and ion mobility spectrometry $[23,24] .{ }^{\circ} \mathrm{CD}^{\circ}$ spectra ${ }^{\circ}$ indicated $^{\circ}$ that ${ }^{\circ}$ the ${ }^{\circ}$ sequences exist as B-DNA in $\mathrm{NH}_{4} \mathrm{OAc} / \mathrm{H}_{2} \mathrm{O}$ solution, but ion mobility spectrometry found that only A-form helices are present for solvent-free 8 to $14 \mathrm{bp}$ duplexes, while duplexes smaller than 8 bp only exist as globular forms. While these results indicate that a B-A transition is occurring from solution to a solvent-free environment for the 8 to $14 \mathrm{bp}$ duplexes, the analysis of larger sequences is required to determine whether B-DNA is ever stable in the absence of solvent. In this study, circular dichroism, mass spectrometry, ion mobility, and molecular dynamics calculations were performed on poly $\mathrm{d}(\mathrm{CG})_{n}$ duplexes and mixed sequence duplexes from 18 to $30 \mathrm{bp}$ long. For simplicity, the strands were named by their sequence and length so CG18 $=\mathrm{d}(\mathrm{CG})_{9}, \mathrm{CG}_{22}=\mathrm{d}(\mathrm{CG})_{11}, \mathrm{CG} 26=\mathrm{d}(\mathrm{CG})_{13}$, CG30 $=\mathrm{d}(\mathrm{CG})_{15}, \operatorname{Mix} 18=\mathrm{dCAGTGAT}(\mathrm{CG})_{2}$ ATCACTG,
Mix22 $=$ dGAC $_{2}$ TAGAT $_{2} \mathrm{CGA}_{2} \mathrm{TCTAG}_{2} \mathrm{TC}, \operatorname{Mix} 26=$ dCAGTCACG $\mathrm{AT}_{2} \mathrm{CGA}_{2} \mathrm{TC}_{2} \mathrm{GTGACTG}_{2}, \mathrm{Mix30a}=$ $\mathrm{dAGA}_{4} \mathrm{~T}_{2} \mathrm{AT}_{2} \mathrm{GTCTG}_{2} \mathrm{CATAGTGCA}_{2} \mathrm{CAG}$, and Mix30b = $\mathrm{dCTGT}_{2}$ GCACTATGC 2 AGACA $\mathrm{AA}_{2} \mathrm{~T}_{4} \mathrm{CT}$.

\section{Experimental}

Materials

The oligonucleotides were purchased from SigmaGenosys (The Woodlands, TX) and used without further purification. They were suspended at a concentration of $300 \mu \mathrm{M}$ in $30 \mathrm{mM} \mathrm{NH} \mathrm{H}_{4} \mathrm{OAc} / \mathrm{H}_{2} \mathrm{O}$ solution $(\mathrm{pH}$ 7.0), annealed at $95^{\circ} \mathrm{C}$ for $10 \mathrm{~min}$, slowly cooled to room temperature, and stored at $10^{\circ} \mathrm{C}$. Before analysis with $\mathrm{CD}$ and mass spectrometry, the duplex solutions were diluted to $50 \mu \mathrm{M}$ with $\mathrm{H}_{2} \mathrm{O}$, and $1 \% \mathrm{NH}_{4} \mathrm{OH}$ was added to induce negative ion formation.

\section{Circular Dichroism Experiments}

Circular dichroism (CD) spectra were measured on an OLIS RSM 1000 Spectrometer (Bogart, GA) using a 0.1 $\mathrm{cm}$ path length quartz cell. The $50 \mu \mathrm{M}$ DNA solutions in $\mathrm{NH}_{4} \mathrm{OAc} / \mathrm{H}_{2} \mathrm{O} / \mathrm{NH}_{4} \mathrm{OH}$ were analyzed by $\mathrm{CD}$ to obtain the conformation of the duplexes before they were sprayed and eventually entered the drift cell of the ESI instrument. The ellipticity of the duplexes was monitored from 200 to $300 \mathrm{~nm}$ to determine the wavelengths where maximum and minimum ellipticity was observed.

\section{Mass Spectra and Ion Mobility Experiments}

Details concerning the experimental setup for the mass spectra and ion mobility measurements have been published ${ }^{\circ}$ previously ${ }^{\circ}[25]^{\circ}{ }^{\circ}$ Accordingly, ${ }^{\circ}$ only ${ }^{\circ} a^{\circ}$ brief $^{\circ}$ description will be given here. Approximately $6>113>\mathrm{L}$ of one of the solutions prepared as described above was placed in a metallized glass needle spray tip. Ions were formed by nano-ESI and injected into a specially designed ion funnel. The ions were then carefully injected into a $4.5 \mathrm{~cm}$ long drift cell filled with $\sim 5$ torr of helium gas and gently pulled through the He gas at a constant drift velocity by a weak electric field. After exiting the drift cell, the ions were mass analyzed in a quadrupole mass filter and detected. The quadrupole mass filter was either set to select a mass range of interest for the acquisition of a mass spectrum or in a pulsed experiment it detected one specific $\mathrm{m} / \mathrm{z}$ as a function of time, yielding an arrival time distribution or ATD. The reduced mobility, $K_{o}$ of a specific ion is accurately determined ${ }^{\circ}$ sing $^{\circ} \mathrm{eq}^{\circ} 1^{\circ}[26]$,

$$
t_{A}=\frac{l^{2}}{K_{o}} \cdot \frac{273.16}{760 T} \cdot \frac{p}{V}+t_{o}
$$

where $l$ is the length of the cell, $T$ is the temperature in Kelvin, $p$ is the pressure of the He gas (in torr), $V$ is the voltage applied to the drift cell, $t_{A}$ is the arrival time of 
the ions taken from the center of the ATD peak, and $t_{o}$ is the amount of time the ion spends outside the drift cell before reaching the detector. A series of arrival times is measured by changing the voltage applied to the drift cell. A plot of $t_{A}$ versus $p / V$ yields a straight line with a slope inversely proportional to $K_{o}$ and an intercept of $t_{o}$. Once $K_{o}$ is determined, the collisional cross section of the ion, $\sigma$, is calculated using eq 2,

$$
\sigma=\frac{3 e}{16 N_{o}}\left(\frac{2 \pi}{\mu k_{b} T}\right)^{1 / 2} \frac{1}{K_{o}}
$$

where $e$ is the charge of the ion, $N_{o}$ is the number density of He at STP, $T$ is temperature, $k_{b}$ is Boltzmann's constant, ${ }^{\circ}$ and ${ }^{\circ} \mu^{\circ}$ is ${ }^{\circ}$ the ${ }^{\circ}$ ion- $\mathrm{He}^{\circ}$ reduced ${ }^{\circ} \operatorname{mass}^{\circ}[26]$.

\section{Theoretical Calculations}

Structural information about the ions is obtained by comparing the experimental cross sections determined from the ATDs to calculated values of theoretical models. Candidate structures of each duplex ion were generated ${ }^{\circ}$ using $^{\circ}$ the ${ }^{\circ}$ parm $99^{\circ}$ force ${ }^{\circ}$ field ${ }^{\circ}[27]^{\circ}$ and ${ }^{\circ}$ the $\mathrm{AMBER}^{\circ} 7^{\circ}[28]^{\circ}$ set $^{\circ}$ of $^{\circ}$ programs. $^{\circ} \mathrm{Canonical}^{\circ} \mathrm{A}^{\circ}$ and $B$-form helix starting geometries were created using the NUCGEN utility within AMBER and Z-forms were generated $^{\circ}$ using $^{\circ} \mathrm{HyperChem}^{\circ}[29]^{\circ}{ }^{\circ} 300^{\circ} \mathrm{K}^{\circ}$ molecular dynamics simulations were run on each complex for 2 ns using the AMBER 7 set of programs, and every 5 ps a structure was saved. Each structure was then energyminimized and its cross section calculated. For ions with more than 200 atoms, collisional cross sections were calculated using hard-sphere scattering and trajectory ${ }^{\circ}$ models ${ }^{\circ}$ developed ${ }^{\circ} y^{\circ}$ the ${ }^{\circ}$ Jarrold ${ }^{\circ}$ group $[30,931]$. In the calculations, the starting structures eventually converged to give one or more steady-state structures where the cross section remains relatively constant. The average cross sections of the final 50 to 100 structures in each steady state were used for comparison with the experimental values.

The experimentally observed overall charge state of the complexes is readily identified from the mass spectra, but the exact locations of the deprotonation sites required for modeling are not known. Thus, the deprotonation sites on the DNA were divided and dispersed among the strands, with at least two neutral phosphate groups $^{\circ}$ between $^{\circ}$ every $^{\circ}$ deprotonated ${ }^{\circ}$ group $^{\circ}[32-36]$. Multiple duplex structures were modeled with many different deprotonation sites, but no theoretical differences in cross section or conformation were observed as a function of charge location, consistent with previously

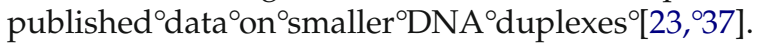

\section{Results and Discussion}

\section{Circular Dichroism}

Circular dichroism (CD) was utilized in determining the solution phase helix conformations of the sequences
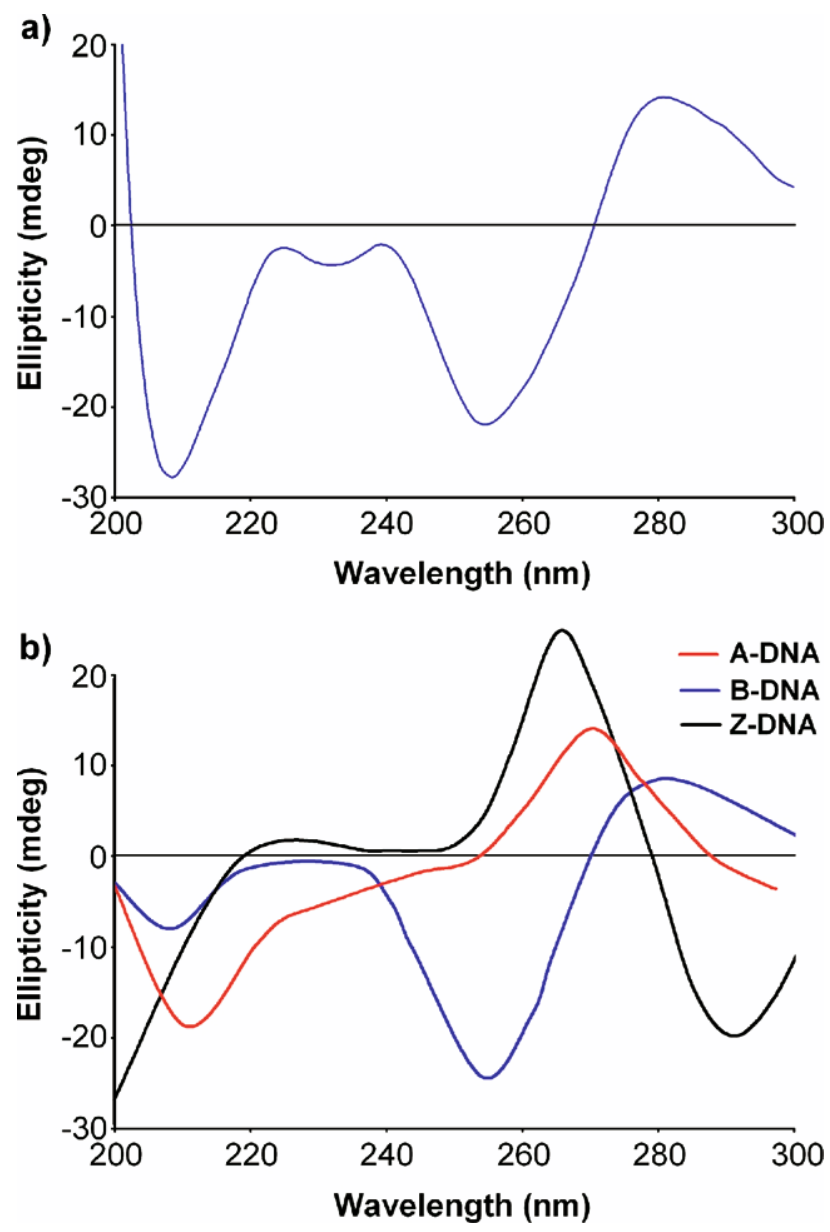

Figure 2. (a) A typical CD spectrum for the 18 to $30 \mathrm{bp}$ sequences analyzed. The spectra shown is for Mix22. (b) Expected CD spectra for A-DNA (red), B-DNA (blue), and Z-DNA (black).

studied. CD is able to characterize whether DNA has an A-, B-, or Z-form helix, since A-DNA has a maximum near $265 \mathrm{~nm}$, B-DNA has a maximum near $280 \mathrm{~nm}$, and Z-DNA has a maximum near $260 \mathrm{~nm}$ as shown in Figure $^{\circ} 2 b^{\circ}[38-42] .{ }^{\circ} \mathrm{A}^{\circ}$ typical ${ }^{\circ} \mathrm{CD}^{\circ}$ spectrum ${ }^{\circ}$ for ${ }^{\circ}$ the sequences ${ }^{\circ}$ analyzed ${ }^{\circ}$ is $^{\circ}$ shown $^{\circ}$ in $^{\circ}$ Figure $^{\circ} 2 a^{\circ} .^{\circ}$ All $^{\circ}$ of ${ }^{\circ}$ the sequences studied had spectra indicative of B-DNA with only small differences in the intensity of the maximum and minimum ellipticity were observed (longer sequences exhibit more intense maxima and minima, probably due to the additional base pairing and stacking interactions).

\section{Mass Spectra}

The nano-ESI mass spectra of CG18 and CG30 are shown $^{\circ}$ in $^{\circ}$ Figure $^{\circ} 3 .^{\circ}$ Deprotonated $^{\circ}$ single $^{\circ}$ strands $^{\circ}$ and duplexes were present in the mass spectra for all of the sequences analyzed with $\mathrm{NH}_{4}^{+}$adducts to the right of each peak. Because the poly $\mathrm{d}(\mathrm{CG})_{n}$ strands and some of the mixed sequences are self-complementary, care must be taken in assigning the peaks in the mass spectra. Duplexes with odd charge states can be unambiguously 


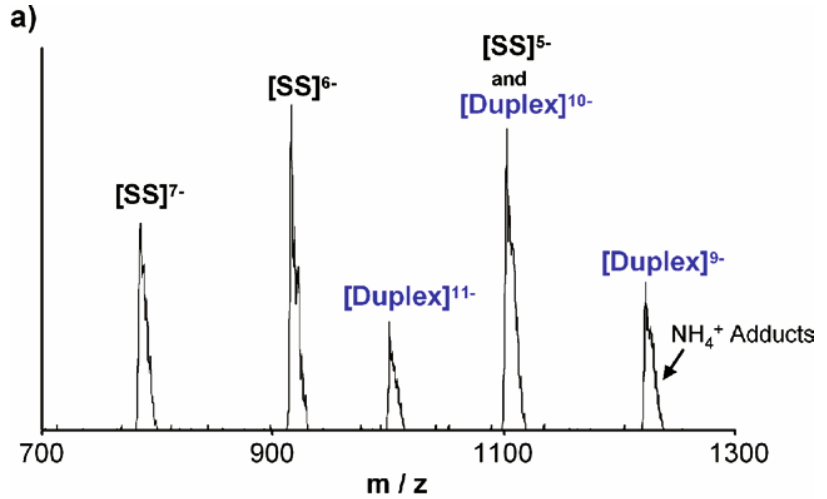

b)

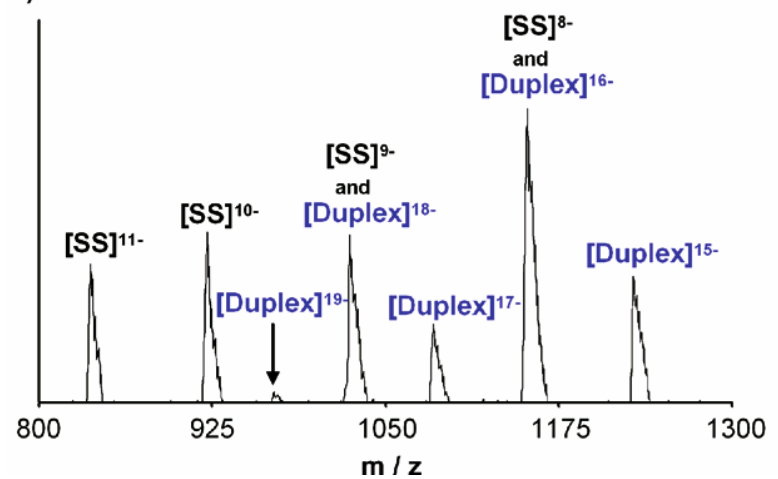

Figure 3. Nano-ESI mass spectra for (a) CG18 and (b) CG30. Single-strand and duplex peaks were observed for all sequences analyzed and the most abundant duplex peak always had a charge state of half the number of base pairs. SS is the abbreviation for single strand.

identified, but the duplexes with even charge states may also correspond to single strands with half the charge state. One interesting observation was that the most abundant charge state of the duplexes in all of the mass spectra collected was always equal to half the number of base pairs (i.e., the most abundant peak for the $18 \mathrm{bp}$ duplexes corresponds to the -9 charge state, while the most abundant peak for the $30 \mathrm{bp}$ duplexes had a -15 charge state).

\section{Ion Mobility}

To examine the conformational properties of the DNA duplexes, ion mobility experiments were performed. In each case, the appropriate ion for each complex was gently injected into the drift cell and its ATD collected.

\section{Poly $d(C G)_{n}$ Duplexes}

ATDs for the CG18, CG22, CG26, and CG30 duplexes in their most abundant odd charge states are shown in Figure ${ }^{\circ} 4 .{ }^{\circ}$ The $^{\circ}$ other $^{\circ}$ less ${ }^{\circ}$ abundant ${ }^{\circ}$ odd $^{\circ}$ charge $^{\circ}$ states ${ }^{\circ}$ for each duplex gave ATDs similar to those shown in Figure $^{\circ} 4,{ }^{\circ}$ while ${ }^{\circ}$ the ${ }^{\circ}$ even $^{\circ}$ charge $^{\circ}$ state $^{\circ}$ were $^{\circ}$ not $^{\circ}$ analyzed because of the presence of single strands. Single peaks were observed in the ATDs for the CG18 and
CG26 duplexes, indicating that most likely only one family of conformers is present. However, two peaks were present for the CG22 and CG30 duplexes, indicative of two conformations, suggesting that some type of conformational change is occurring at these sequence lengths. The collision cross sections of the most abundant $^{\circ}$ charge $^{\circ}$ state $^{\circ}$ for $^{\circ}$ each $^{\circ}$ duplex $^{\circ}$ are $^{\circ}$ listed ${ }^{\circ}$ in $^{\circ}$ Table $^{\circ} 1$. Cross sections for the other odd charge-state duplexes present in the mass spectra were also evaluated, and it was found that as the charge state of each complex becomes more negative, an enlargement in cross section of $\sim 1 \%$ per odd charge state occurs. These results are shown ${ }^{\circ}$ for ${ }^{\circ}$ the $^{\circ} 22^{\circ}$ and $^{\circ} 26^{\circ}$ bp $^{\circ}$ duplexes ${ }^{\circ}$ in $^{\circ}$ Table $^{\circ} 2 .^{\circ}$ As observed from other biological systems studied with ion $^{\circ}$ mobility $^{\circ}$ and $^{\circ}$ theoretical ${ }^{\circ}$ calculations $^{\circ}\left[43,{ }^{\circ} 44\right]$, , this increase in cross section is due to the increase in charge repulsion between strands. Thus, only the lowest charge state duplex structures were analyzed theoretically.

Theoretical modeling was utilized to understand

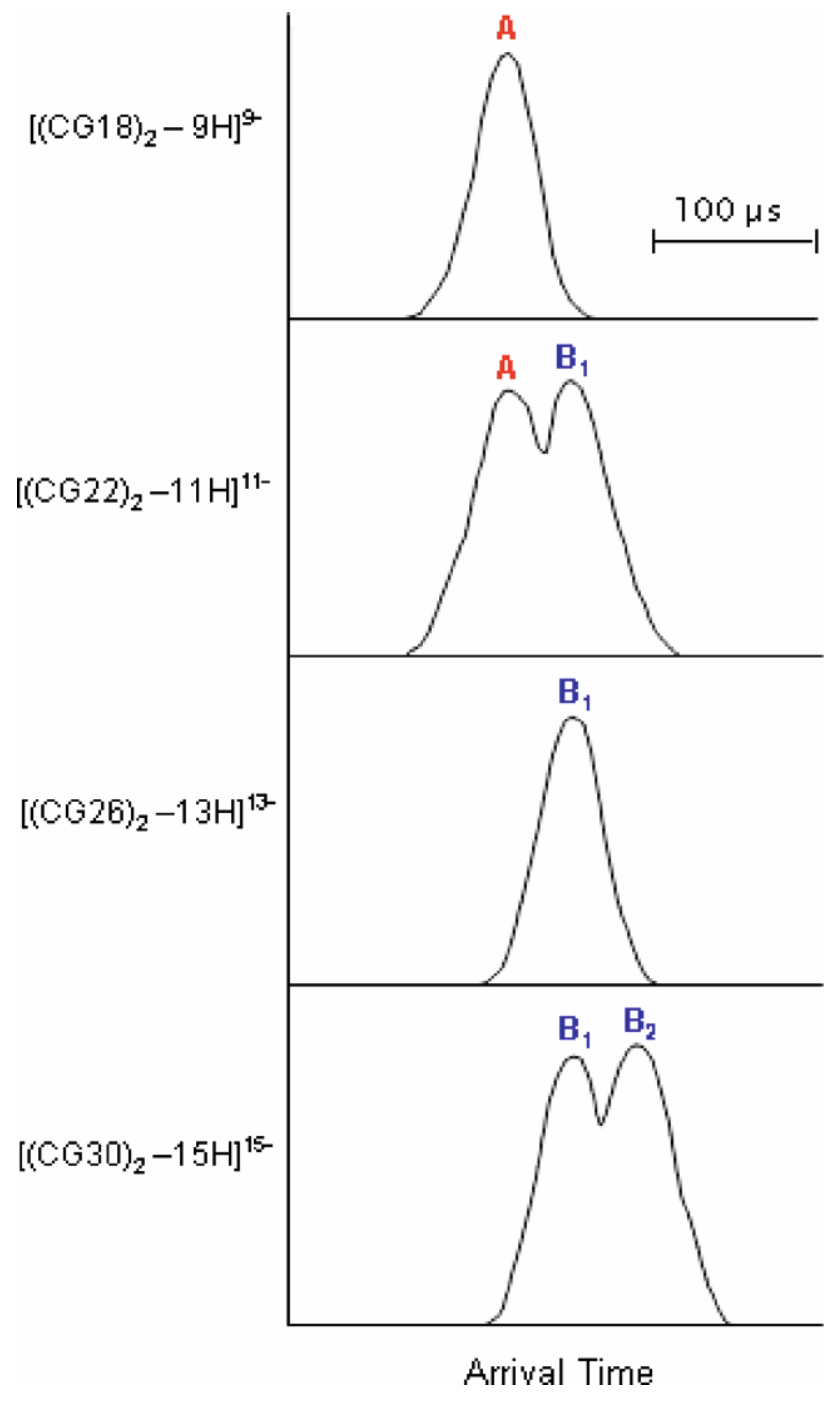

Figure 4. ATDs for the $18,22,26$, and 30 bp poly $d(C G)$ duplexes. The labels $A, B_{1}$, and $B_{2}$ refer to the type of helix observed (see text). 
Table 1. Experimental and theoretical cross sections $\left(\AA^{2}\right)$ of the duplexes

\begin{tabular}{lrrrr}
\hline & & \multicolumn{4}{c}{ Theory $^{\text {bcd }}$} \\
\cline { 3 - 5 } \multicolumn{1}{c}{ Duplex } & Expt $^{\text {a }}$ & A-helix & B-helix & Z-helix \\
\hline \hline$\left[(\mathrm{CG} 18)_{2}-9 \mathrm{H}\right]^{9-}$ & 1268 & 1254 & 1221 & 1305 \\
{$\left[(\mathrm{CG} 2)_{2}-11 \mathrm{H}\right]^{11-}$} & 1403 & & & \\
& 1558 & 1395 & 1549 & 1600 \\
{$\left[(\mathrm{CG} 26)_{2}-13 \mathrm{H}\right]^{13-}$} & 1763 & 1635 & 1750 & 1720 \\
{$\left[(\mathrm{CG} 30)_{2}-15 \mathrm{H}\right]^{15-}$} & 1948 & & 1950 & \\
& 2249 & 1875 & 2240 & 2000 \\
{$\left[(\mathrm{Mix} 18)_{2}-9 \mathrm{H}\right]^{9-}$} & 1227 & & & \\
& 1319 & 1221 & 1315 & 1263 \\
{$\left[(\mathrm{Mix} 22)_{2}-11 \mathrm{H}\right]^{11-}$} & 1529 & 1486 & 1524 & 1458 \\
{$\left[(\mathrm{Mix} 26)_{2}-13 \mathrm{H}\right]^{13-}$} & 1776 & & 1764 & \\
& 2020 & 1676 & 2035 & 1812 \\
{$[\text { Mix30a } \cdot \mathrm{Mix30b-15H}]^{15-}$} & 2203 & & 2190 & \\
& 2406 & 1950 & 2375 & 2070 \\
\hline
\end{tabular}

a $1 \%$ reproducibility error.

$\mathrm{b}^{\mathrm{b}} \leq 2 \%$ standard deviation.

'Similar cross sections were observed for the duplexes of other odd charge states.

${ }^{\mathrm{d}}$ Two different families of B-helices were observed (see text and Figure 6).

why two conformations were present for the CG22 and CG30 duplexes, while only one conformer occurred for the other duplexes. To evaluate these conformations, A-, B-, and Z-form helices for each duplex were analyzed with $300 \mathrm{~K}$ molecular dynamics simulations. Only one steady state was observed in the dynamics plots for all of the A-, B-, and Z-form helices, except when a B-helix starting structure was used for $(\mathrm{CG} 30)_{2}$. An example plot of cross section versus time with one steady $^{\circ}$ state $^{\circ}$ is ${ }^{\circ}$ shown $^{\circ}$ in ${ }^{\circ}$ Figure $^{\circ} 5 a^{\circ}$ for ${ }^{\circ}$ the ${ }^{\circ}$ B-helix starting structure of (CG18) ${ }_{2}$, and the dynamics plot for the B-helix starting structure of (CG30) $)_{2}$ with two

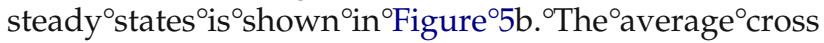
section of the final 50 to 100 structures for each steady state $^{\circ}$ is $^{\circ}$ listed ${ }^{\circ}$ in $^{\circ}$ Table ${ }^{\circ} 1$.

When the theoretical structures for the different helix forms of each duplex were analyzed, it was found that the resulting helices at the end of the dynamics simulations were similar to the starting solution helices for the A- and Z-forms. However, the B-form helices for the CG18, CG22, and CG26 duplexes were different from their starting solution helices as they all had a bend near

Table 2. Experimental cross sections $\left(\AA^{2}\right)$ of 22 and 26 bp duplexes versus charge state ${ }^{\mathrm{a}}$

\begin{tabular}{|c|c|c|c|}
\hline \multirow[b]{2}{*}{ Duplex } & \multicolumn{3}{|c|}{ Charge state } \\
\hline & -11 & -13 & -15 \\
\hline \multirow[t]{2}{*}{$(\mathrm{CG} 22)_{2}$} & 1403 & 1411 & \\
\hline & 1558 & 1567 & - \\
\hline$(\operatorname{Mix} 22)_{2}$ & 1529 & 1542 & - \\
\hline$(\mathrm{CG} 26)_{2}$ & - & 1763 & 1779 \\
\hline \multirow{2}{*}{$(\operatorname{Mix} 26)_{2}$} & & 1776 & 1784 \\
\hline & - & 2020 & 2031 \\
\hline
\end{tabular}

${ }^{a} 1 \%$ reproducibility error.
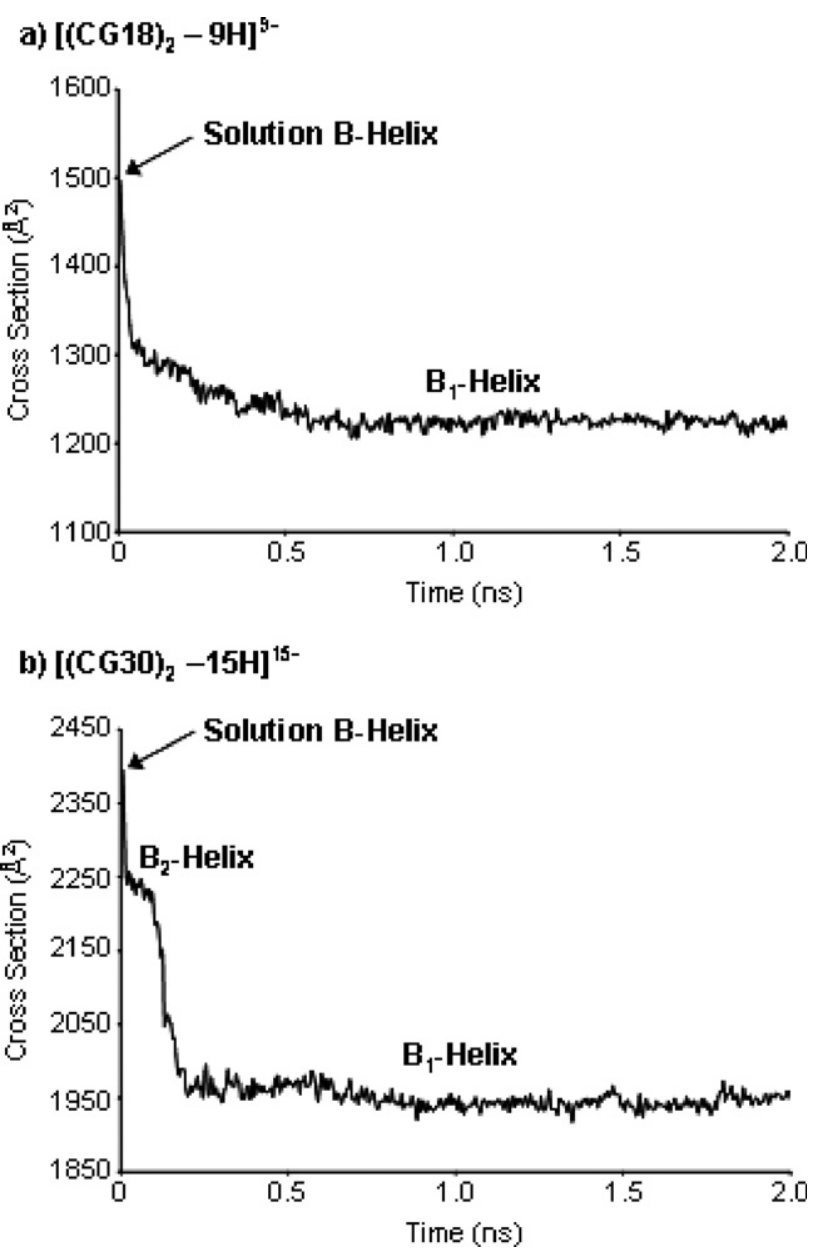

Figure 5. $300 \mathrm{~K}$ dynamics plots of cross section versus dynamics time for (a) the CG18 duplex and (b) the CG30 duplex. In both cases, a solution form B-helix starting structure was used. Only one steady state was observed for the CG18 duplex, but two steady states were present for the CG30 duplex. The dynamics simulations were run for $2 \mathrm{~ns}$ and every $5 \mathrm{ps}$ a structure was saved and its cross section calculated. Analysis of the resulting structures allowed the structural assignments given in the Figure (see text and $^{\circ}$ Figure 6 ).

the end of their helices. Two forms of the CG30 B-form helix ${ }^{\circ}$ were ${ }^{\circ}$ observed ${ }^{\circ}$ in $^{\circ}$ the ${ }^{\circ}$ dynamics $^{\circ}$ plot $^{\circ}$ in $^{\circ}$ Figure $^{\circ} 5 \mathrm{~b}$, where the initial $B_{2}$ conformer $\left(2240 \AA^{2}\right.$ is similar in structure to the solution B-helix, but after $\sim 200 \mathrm{ps}$ it converts into a helix with a bend at the end $\left(\mathrm{B}_{1}\right.$ conformer, $1950 \AA^{2}$, analogous to the solvent-free Bform helices for the smaller poly $\mathrm{d}(\mathrm{CG})_{n}$ duplexes. The $\mathrm{B}_{2}$ conformation for CG30 is considered a steady-state structure in dynamics calculation because it endures for a significant time before isomerizing to $B_{1}$. It does appear that the AMBER force field predicts $B_{1}$ to be more stable than $B_{2}$ based on our 2 nanosecond simulation but that may either be a force field effect or attributable to the necessarily limited time of the dynamics run. Clearly, the $B_{2}$ conformer is observed experimentally supporting its long-term stability (see below). Conversely, in the simulations for CG18, CG22 and CG26, the solution form B-helix starting structure 
immediately converts to a single B-form helix and retains that structure for the entire dynamics run.

When the experimental cross sections for the duplexes were compared with their theoretical values, a trend was observed for the data. A-form helices correlated with the experimental cross sections for $(\mathrm{CG} 18)_{2}$ and the shortest time peak for $(\mathrm{CG} 22)_{2}$. However, the longer time peak for $(\mathrm{CG} 22)_{2}$ agreed with a bent B-form helix (termed $B_{1}$ ), indicating that at the $22 \mathrm{bp}$ length B-DNA is finally stable in a solution-free environment. The single peak for (CG26) 2 and the two experimental cross sections for $(\mathrm{CG} 30)_{2}$ also correlate with B-helices: the bent $B_{1}$ form matched with the experimental cross section for $(C G 26)_{2}$ and the shorter time peak in the $(\mathrm{CG} 30)_{2}$ ATD, and the near solution $\mathrm{B}_{2}$ form correlated with the cross section for the longer time ATD peak for $(\mathrm{CG} 30)_{2}$. The model A- and Z-form helices for (CG26) and $(\mathrm{CG} 30)_{2}$ did not agree with any of the measured cross sections. Theoretical structures for the helices that correlated with the experimental cross sections of each sequence ${ }^{\circ}$ are ${ }^{\circ}$ illustrated ${ }^{\circ}$ in $^{\circ}$ Figure $^{\circ} 6$.

Previous ion mobility data have illustrated that solvent-free helices first appear for the 8 bp poly d(CG) duplex, while smaller duplexes only occur as globular structures ${ }^{\circ}[23] .{ }^{\circ}$ This $^{\circ}$ data $^{\circ}$ also $^{\circ}$ showed $^{\circ}$ that $^{\circ}$ for ${ }^{\circ}$ the a) $\left[(\mathrm{CG} 18)_{2}-9 \mathrm{H}\right]^{9-}$

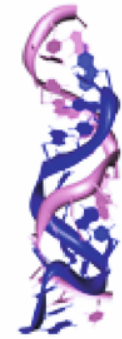

A-form

$\sigma=1254$ म 2

c) $\left[(\mathrm{CG} 26)_{2}-13 \mathrm{H}\right]^{13-}$

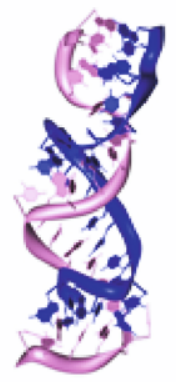

$B_{1}$-form
$\sigma=1750$ H 2 b) $\left[(\mathrm{CG} 22)_{2}-11 \mathrm{H}\right]^{11-}$
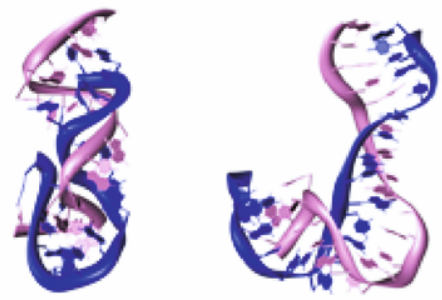

A-form

$\sigma=1395 \mathrm{Az}$

$$
\begin{gathered}
B_{1} \text {-form } \\
\sigma=1549 \mathrm{~A}^{2}
\end{gathered}
$$

d)
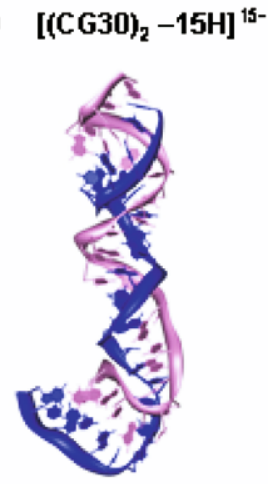

$B_{1}-$ form

$\sigma=1950 \mathrm{~B} 2$

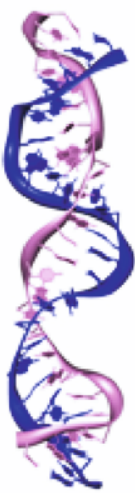

$B_{2}$-form

$\sigma=2240 \mathrm{Az}$
Figure 6. Theoretical structures from the $300 \mathrm{~K}$ dynamics for the (a) CG18, (b) CG22, (c) CG26, and (d) CG30 duplexes that match the experimental cross sections. One strand is blue and the other is pink.

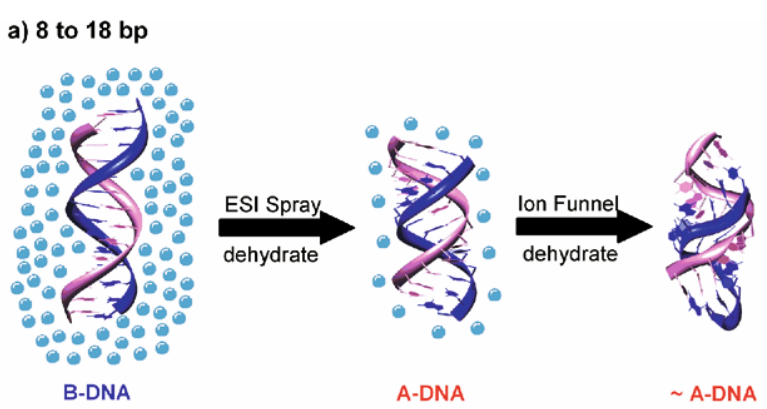

b) Starting at $22 \mathrm{bp}$

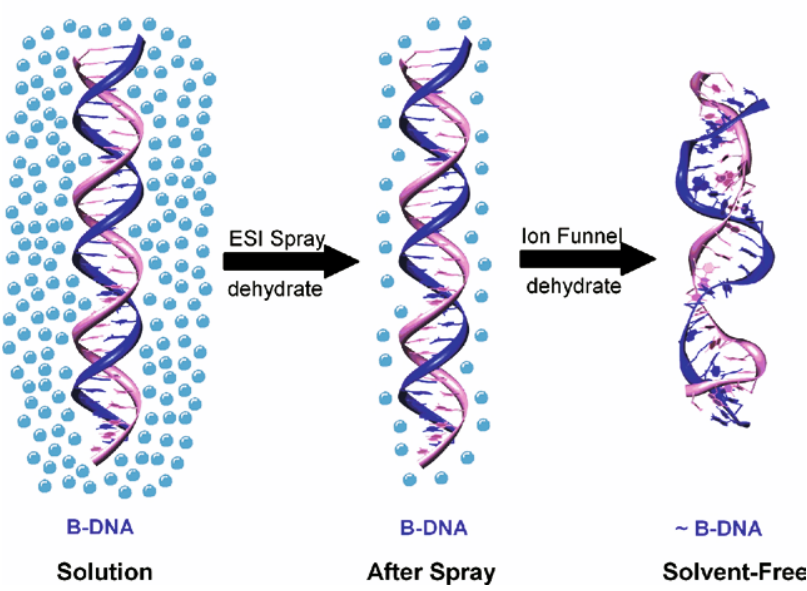

Figure 7. Summary of the poly $d(C G)$ duplexes analyzed. (a) For the CG duplexes from $8 \mathrm{bp}$ to $18 \mathrm{bp}$, only A-form helices were observed without solvent. (b) The first B-form helix was observed for CG duplexes at $22 \mathrm{bp}$ and B-helices were detected exclusively at $26 \mathrm{bp}$ and above.

$\mathrm{d}(\mathrm{CG})_{n}$ sequences from 8 to $18 \mathrm{bp}$ duplex, a B-A transition occurred from solution to the solvent-free environment ${ }^{\circ}$ of $^{\circ}$ the ${ }^{\circ}$ experiment $^{\circ}\left(\right.$ Figure $^{\circ}$ 7a).$^{\circ}{ }^{\circ}$ This ${ }^{\circ} \mathrm{B}-\mathrm{A}$ transition has been observed for other small DNA duplexes when the relative humidity of the solution is decreased ${ }^{\circ}[45-48],{ }^{\circ}$ so $^{\circ}$ it $^{\circ}$ is ${ }^{\circ}$ not $^{\circ}$ unreasonable ${ }^{\circ}$ to presume that smaller duplexes can change from a B-form to an A-form during the desolvation process that occurs in ESI. However, in this study we observed that for the CG22 duplex both an A- and B-form are present in the experiment and only B-DNA is present in $\mathrm{d}(\mathrm{CG})_{n}$ duplexes longer than $22 \mathrm{bp}$. From these results, apparently larger duplexes with increased base pair stacking are able to retain their B-form helix throughout the desolvation and analysis process, resulting in an only modestly transformed B-form helix at the end of the experiment. ${ }^{\circ}$ Figure ${ }^{\circ} 7 \mathrm{~b}^{\circ}$ illustrates ${ }^{\circ}$ this ${ }^{\circ}$ trend.

\section{Mixed Sequence Duplexes}

Since it has been observed that sequences rich in G-C pairs are more A-philic than sequences rich in A-T pairs, the helix forms of sequences with A-T pairs must be evaluated to understand how sequence composition effects ${ }^{\circ}$ the ${ }^{\circ}$ solvent-free ${ }^{\circ} \mathrm{B}-\mathrm{A}^{\circ}$ transition $^{\circ}\left[20-22 .^{\circ}{ }^{\circ}\right.$ The ATDs for a series of mixed duplexes in their most odd 
abundant ${ }^{\circ}$ charge ${ }^{\circ}$ states ${ }^{\circ}$ areshownin $^{\circ}$ Figure 8 . Similar'to the poly $\mathrm{d}(\mathrm{CG})_{n}$ duplexes, the less abundant odd charge states for each duplex gave ATDs similar to those shown. The even charge states were not analyzed because of the presence of single strands. Two peaks were observed in all of the ATDs for the mixed duplexes, except for the Mix22 duplex, which only had a single peak. The experimental cross sections are given in ${ }^{\circ}$ Table ${ }^{\circ} 1$.

Theoretical modeling was utilized to understand the helix conformations of the mixed sequence duplexes. Only one steady state was observed in the dynamics plots for all of the A-, B-, and Z-form helices, except the B-forms of the Mix26 and Mix30 duplexes, which displayed two steady states similar to the CG30 duplex in Figure ${ }^{\circ} 5 b^{\circ} .^{\circ}$ The $^{\circ}$ average ${ }^{\circ}$ cross $^{\circ}$ section $^{\circ}$ of $^{\circ}$ each $^{\circ}$ form $^{\circ}$ is given $^{\circ}$ in $^{\circ}$ Table $^{\circ} 1 .^{\circ}$ When $^{\circ}$ the $e^{\circ}$ theoretical ${ }^{\circ}$ cross $^{\circ}$ sections were compared with the experimental values for each duplex, the shorter time peak for the Mix18 duplex matched the A-helix and the longer peak agreed with a B-form helix. However, the Mix22, Mix26, and Mix30 duplexes only correlated with B-form helices. The DNA helices that match the experimental cross sections are

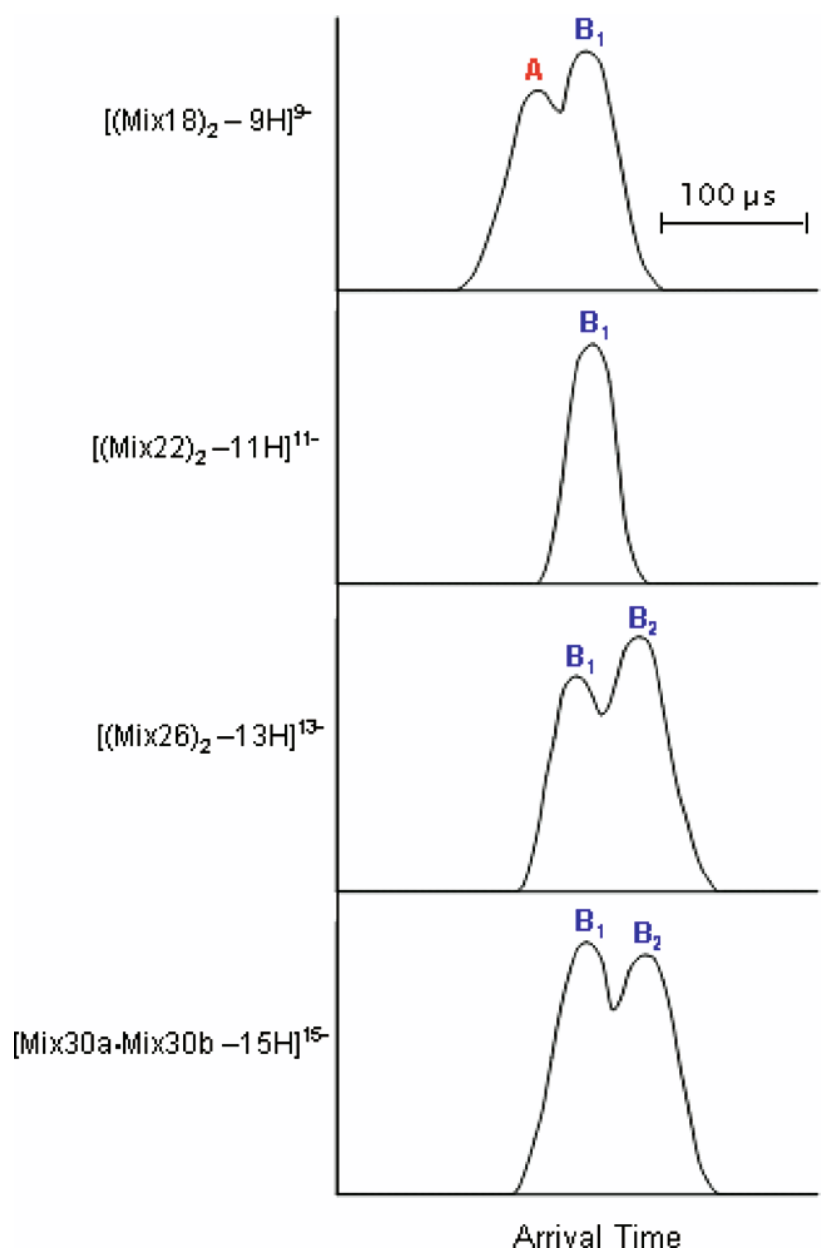

Figure 8. ATDs for the mixed 18, 22, 26, and $30 \mathrm{bp}$ duplexes. The labels $A, B_{1}$, and $B_{2}$ refer to the type of helix observed (see text and Figure ${ }^{\circ}$ ).

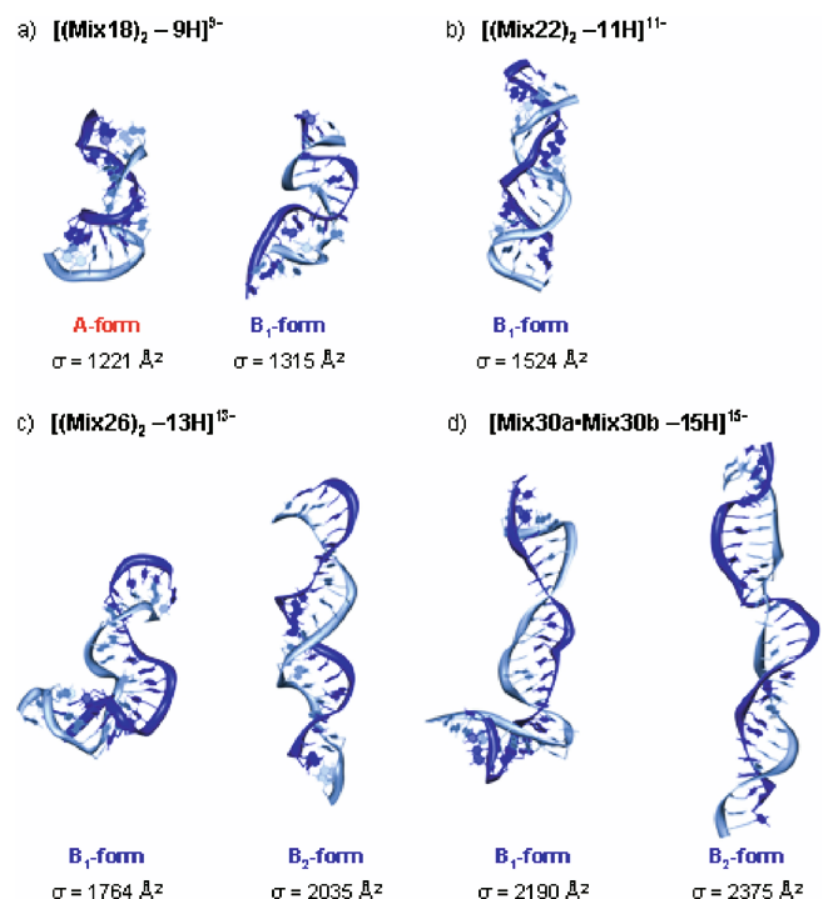

Figure 9. Theoretical structures from the $300 \mathrm{~K}$ dynamics for the (a) Mix18, (b) Mix22, (c) Mix26, and (d) Mix30 duplexes that match the experimental cross sections. One strand is dark blue and the other is light blue.

shown ${ }^{\circ}$ in $^{\circ}$ Figure $^{\circ} 9 . .^{\circ}$ The $^{\circ}$ two ${ }^{\circ}$ theoretical ${ }^{\circ} \mathrm{B}$-helix ${ }^{\circ}$ structures for the Mix 26 and Mix30 duplexes, $\mathrm{B}_{1}$ and $\mathrm{B}_{2}$, were analyzed to determine the conformational change occurring. Analogous to $(\mathrm{CG} 30)_{2}$, the larger conformer $\left(B_{2}\right)$ was an elongated helix similar to the solution B-helix, while the smaller conformer $\left(\mathrm{B}_{1}\right)$ had a bent end. When these two conformers were compared with the two experimental cross sections, the $B_{1}$ conformers agreed with the smaller value and the $B_{2}$ structures matched the larger cross sections for both the Mix26 and Mix30 duplexes.

When the results from the solvent-free poly $\mathrm{d}(\mathrm{CG})_{n}$ helices and mixed helices were compared, an important finding was observed. Both sequence types have Aform helices present at smaller sequence lengths. However, B-form helices first appear at $18 \mathrm{bp}$ for the mixed sequence duplexes, while B-helices are not present for the poly $\mathrm{d}(\mathrm{CG})_{n}$ helices until $22 \mathrm{bp}$. Since B-DNA is observed at smaller helix sizes in the mixed sequence duplexes (with some A-T pairs) than for the pure $\mathrm{d}(\mathrm{CG})_{n}$ duplexes, it can be concluded that the solution trend of G-C pairs being more A-philic than A-T pairs is also relevant to the solvent-free helices and consequently is an intrinsic property of the duplexes, not a solvent effect.

\section{Summary}

The mass spectrometry, ion mobility, and molecular dynamics results presented provide insight into the size- and sequence-dependent conformations of DNA 
helices upon dehydration. The main conclusions are illustrated below.

(1) $\mathrm{d}(\mathrm{CG})_{n}$ duplexes between 8 and 18 bp have B-form helices in solution and convert to an A-form helix in a solvent-free environment. However, starting at the $22 \mathrm{bp}$ duplex, a bent form B-helix becomes stable without solvent and at $30 \mathrm{bp}$ a solution like B-helix first appears.

(2) For the mixed sequences with both C-G and A-T pairs, the bent $\mathrm{B}$-form helix becomes stable at the $18 \mathrm{bp}$ duplex and the solution form B-helix at the $26 \mathrm{bp}$ duplex, indicating that A-T pairs are less A-philic than C-G pairs. This is an intrinsic property and not a solvent effect.

(3) Solution B-form helices are conserved without solvent, but the length at which the helices are preserved is sequence- and size-dependent.

\section{Acknowledgments}

The authors gratefully acknowledge the support of the National Science Foundation under grant CHE-0503728.

\section{References}

1. Watson, J. D.; Crick, F. H. Molecular Structure of Nucleic Acids: A Structure for Deoxyribose Nucleic Acid. Nature 1953, 171, 737

2. Langridge, R.; Wilson, H. R.; Hooper, C. W.; Wilkins, M. H. F. Hamilton, L. D. The Molecular Configuration of Deoxyribonucleic Acid. I. X-ray Diffraction Study of a Crystalline Form of the Lithium Salt. J. Mol. Biol. 1960, 2, 19-37.

3. Langridge, R.; Marvin, D. A.; Seeds, W. E.; Wilson, H. R.; Hamilton, L. D. The Molecular Configuration of Deoxyribonucleic Acid. II. Molecular Models and their Fourier Transforms. J Mol. Biol. 1960, 2, 38

4. Fuller, W.; Wilkins, M. H. F.; Wilson, H. R.; Hamilton, L. D.; Arnott, S. The Molecular Configuration of Deoxyribonucleic Acid. IV. X-ray Diffraction Study of the A Form. J. Mol. Biol. 1965, 12, 60

5. Wang, A. H. J.; Quigley, G. J.; Kolpak, F. J.; Crawford, J. L.; vanBoom, J. H.; van der Marel, G.; Rich, A. Molecular Structure of a Left-Handed Double Helical DNA Fragment at Atomic Resolution. Nature 1979, 282, 680

6. Franklin, R. E.; Gosling, R. G. The structure of sodium thymonucleate fibers. I. The influence of water content. Acta Crystallogr. 1953, 6, 673

7. Kim, Y.; Geiger, J. H.; Hahn, S.; Sigler, P. B. Crystal Structure of a Yeast TBP/TATA-Box Complex. Nature 1993, 365, 512.

8. Kim, J. L.; Nikolov, D. B.; Burley, S. K. Cocrystal Structure of TBP Recognizing the minor groove of a TATA element. Nature 1993, 365, 520.

9. Florentiev, V. L.; Ivanov, V. I. RNA Polymerase: Two-step Mechanism with Overlapping Steps. Nature 1970, 228, 519.

10. Beabealashvily, R. S.; Ivanov, V. I.; Minchenkova, L. E.; Savotchkina, L. P. RNA polymerase-DNA complexes I. The study of the conformation of nucleic acids at the growing point of RNA in an RNA polymeraseDNA system. Biochim. Biophys. Acta 1972, 259, 35.

11. Setlow, P. DNA in dormant spores of Bacillus species is in an A-like conformation. Mol. Microbiol. 1992, 6, 563.

12. Ivanov, V. I.; Minchenkova, L. E.; Chernov, B. K.; McPhie, P.; Ryu, S.; Garges, S.; Barber, A. M.; Zhurkin, V. B.; Adhya, S. CRP-DNA Complexes: Inducing the A-like Form in the Binding Sites with an Extended Central Spacer. J. Mol. Biol. 1995, 245, 228.

13. Eom, S. H.; Wang, J.; Steitz, T. A. Structure of Taq polymerase with DNA at the Polymerase Active Site. Nature 1996, 382, 278

14. Jones, S.; Heyningen, P.; Berman, H. M.; Thornton, J. M. Protein-DNA Interactions: A Structural Analysis. J. Mol. Biol. 1999, 287, 877.

15. Brahm, J.; Mommaerts, W. F. H. M. A Study of Conformation of Nucleic Acids in Solution by Means of Circular Dichroism. J. Mol. Biol. 1964, 10, 73.

16. Ivanov, V. I.; Minchenkova, L. E.; Minyat, E. E.; Frank-Kamenetskii, M. D.; Schyolkina, A. K. The B to A Transition of DNA in Solution. J. Mol. Biol. 1974, 87, 817

17. Vorlickova, M.; Minyat, E. E.; Kypr, J. Cooperative Changes in the Chiroptical Properties of DNA Induced by Methanol. Biopolymers, 1984, 23,1 .

18. Minyat, E. E.; Ivanov, V. I.; Kritzyn, A. M.; Minchenkova, L. E.; Schyolkina, A. K. Spermine and Spermidine-Induced B to A Transition of DNA in Solution. J. Mol. Biol. 1978, 128, 397.
19. Xu, Q.; Shoemaker, R. K.; Braunlin, W. H. Induction of B-A transitions of Deoxyoligonucleotides by Multivalent Cations in Dilute Aqueous Solution Biophys. J. 1993, 65, 1039.

20. Ivanov, V. I.; Minchenkova, L. E. The A-form of DNA-In search of Biological Role (A Review). Mol. Biol. 1995, 28, 780.

21. Gorin, A. A.; Ulyanov, N. B.; Zhurkin, V. B. S-N Transition of the Sugar Ring in B-form DNA. Mol. Biol. 1990, 24, 1036.

22. Foloppe, N.; MacKerell, A. D. Intrinsic Conformational Properties of Deoxyribonucleosides: Implicated Role for Cytosine in the Equilibrium Among the A, B, and Z Forms of DNA. Biophys. J. 1999, 76, 3206.

23. Gidden, J.; Ferzoco, A. Baker, E. S.; Bowers, M. T. Duplex Formation and the Onset of Helicity in Poly d(CG) Oligonucleotides in a Solvent-Free Environment J. Am. Chem. Soc. 2004, 126, 15132.

24. Gidden, J.; Baker, E. S.; Ferzoco, A.; Bowers, M. T. Structural Motifs of DNA Complexes in the Gas Phase Int. J. Mass Spectrom. 2005, 240, 183.

25. Wyttenbach, T.; Kemper, P. R.; Bowers, M. T. Design of a New Electrospray Ion Mobility Mass Spectrometer Int. J. Mass Spectrom. 2001 $212,13$.

26. Mason, E. A.; McDaniel, E. W. Transport Properties of Ions in Gases; Wiley: New York, NY, 1988.

27. Cheatham, T. E.; Cieplak, P.; Kollman, P. A. J. Biomol. Struct. Dyn. 1999, 16,8458 .

28. Case, D. A.; Pearlman, D. A.; Caldwell, J. W.; Cheatham T. E., III; Wang J.; Ross, W. S.; Simmerling, C. L.; Darden, T. A.; Merz, K. M.; Stanton, R. V.; Cheng, A. L.; Vincent, J. J.; Crowley, M.; Tsui, V.; Gohlke, H. Radmer, R. J.; Duan, Y.; Pitera, J.; Massova, I.; Seibel, G. L.; Singh, U. C.; Weiner, P. K.; Kollman, P. A. AMBER 7; University of California: San Francisco, CA, 2002.

29. HyperChem 7.0; Hypercube Inc., Gainesville, FL.

30. Mesleh, M. F.; Hunter, J. M.; Shvartsburg, A. A.; Schwartz, G. C.; Jarrold, M. F. Structural Information from Ion Mobility Measurements: Effects of the Long-Range Potential J. Phys. Chem. 1996, 100, 16082

31. Shvartsburg, A. A.; Jarrold, M. F. An Exact Hard-Spheres Scattering Model for the Mobilities of Polyatomic Ions. Chem. Phys. Lett. 1996, 261, 86.

32. Maher, L. J.; Wold, B.; Dervan, P. B. Inhibition of DNA Binding Proteins by Oligonucleotide-Directed Triple Helix Formation. Science 1989, 245, 725 .

33. Demidov, V. V.; Potaman, V. N.; Frank-Kamenetskii, M. D.; Egholm. M.; Buchard, O.; Sönnichsen, S. H.; Nielsen, P. E. Stability of Peptide Nucleic Acids in Human Serum and Cellular Extracts. Biochem. Pharmacol. 1994, 48, 1310 .

34. Tyagi, S.; Kramer, F. R. Molecular Beacons: Probes that Fluoresce upon Hybridization. Nat. Biotechnol. 1996, 14, 303.

35. Holland, P. M.; Abramson, R. D.; Watson, R.; Gefland, D. H. Detection of Specific Polymerase Chain Reaction Product by Utilizing the $5^{\prime} \rightarrow 3^{\prime}$ Exonuclease Activity of Thermus aquaticus DNA Polymerase. Proc. Natl. Acad. Sci. U.S.A. 1991, 88, 7276.

36. Thelwell, N.; Millington, S.; Solinas, A.; Booth, J.; Brown, T. Mode of Action and Application of Scorpion Primers to Mutation Detection. Nucleic Acids Res. 2000, 28, 3752.

37. Rueda, M.; Kalko, S. G.; Luque, F. J.; Orozco, M. The Structure and Dynamics of DNA in the Gas Phase. J. Am. Chem. Soc. 2003, 125, 8007.

38. Veenstra, T. D. Electrospray Ionization Mass Spectrometry: A Promising New Technique in the Study of Protein/DNA Noncovalent Complexes. Biochem. Biophys. Res. Commun. 1999, 257, 1.

39. Riazance, J. H.; Baase, W. A.; Johnson, W. C., Jr.; Hall, K.; Cruz, P. Tinoco, I., Jr. Evidence for Z-form RNA by vacuum UV circular dichroism. Nucleic Acids Res. 1985, 13, 4983

40. Segersnolten, G.M.J.; Sijtsema, N. M.; Otto, C. Evidence for Hoogsteen GC Base Pairs in the Proton-Induced Transition from Right-Handed to Left-Handed Poly(dG-dC).Poly(dG-dC). Biochemistry 1997, 36, 13241.

41. Poehl, F. M.; Jovin, T. M. Salt-Induced Cooperative Conformational Change of a Synthetic DNA: Equilibrium and Kinetic Studies with Poly(dG-dC). J. Mol. Biol. 1972, 67, 375.

42. Trantirek, L.; Stefl, R.; Vorlickova, M.; Koca, J.; Sklenar, V.; Kypr, J. An A-type Double Helix of DNA Having B-Type Puckering of the Deoxyribose Rings. J. Mol. Biol. 2000, 297, 907.

43. Baker, E. S.; Hong, J. W.; Gaylord, B. S.; Bazan, G. C.; Bowers, M. T. PNA/dsDNA Complexes: Site-Specific Binding and dsDNA Biosensor Applications. J. Am. Chem. Soc. 2006, 128, 8484.

44. Baker, E. S.; Bernstein, S. L.; Gabelica, V.; De Pauw, E.; Bowers, M. T. G-Quadruplexes in Telomeric Repeats Are Conserved in a Solvent-Free Environment. Int. J. Mass Spectrom. 2006, 253, 225.

45. Schnier, P. D.; Klassen, J. S.; Strittmatter, E. F.; Williams, E. R. Activation Energies for Dissociation of Double Strand Oligonucleotide Anions: Evidence for Watson-Crick Base Pairing in Vacuo. I. Am. Chem. Soc. 1998, 120, 9605

46. Gabelica, V.; De Pauw, E. Comparison Between Solution-Phase Stability and Gas-Phase Kinetic Stability of Oligodeoxynucleotide Duplexes. J. Mass Spectrom. 2001, 36, 397.

47. Gabelica, V.; Rosu, F.; Houssier, C.; De Pauw, E. Gas-Phase Therma Denaturation of an Oligonucleotide Duplex and Its Complexes with Minor Groove Binders. Rapid Commun. Mass Spectrom. 2000, 14, 464.

48. Gabelica, V.; De Pauw, E. Collision-Induced Dissociation of 16-mer DNA Duplexes with Various Sequences: Evidence for Conservation of the Double Helix Conformation in the Gas Phase. Int. J. Mass Spectrom. 2002, 219, 151 . 